\title{
STRESS RESPONSE IN RAINBOW TROUT DURING INFECTION WITH ICHTHYOPHTHIRIUS MULTIFILIIS AND FORMALIN BATH TREATMENT
}

\author{
Thomas R. JØRGENSEN* and Kurt BUCHMANN
}

\author{
Department of Veterinary Pathobiology, Section of Fish Diseases, University of Copenhagen, \\ Faculty of Life Sciences, Frederiksberg, Denmark
}

Jørgensen T.R., Buchmann K. 2007. Stress response in rainbow trout during infection with Ichthyophthirius multifiliis and formalin bath treatment. Acta Ichthyol. Piscat. 37 (1): 25-28.

\begin{abstract}
Background. Ectoparasitic infections of fish are considered to be stress inducing. However, only a few studies have addressed this topic. In addition, formalin bath treatment of rainbow trout is a generally applied method of controlling ectoparasites, but the stress response in rainbow trout, Oncorhynchus mykiss, as a result of such treatments with formalin, has not received much attention and therefore needs further elucidation. The present investigation addresses the stress-response induced by parasites and formalin treatment.

Materials and methods. Concentrations of plasma cortisol were monitored using ELISA. Samples were taken from groups subjected to confinement stress, infection with Ichthyophthirius multifiliis and formalin bath treatment.

Results. Rainbow trout clearly responded to harmful stimuli by increasing plasma cortisol concentrations. Confinement, formalin bath treatment, as well as infection with Ichthyophthirius multifiliis resulted in significant high cortisol concentrations in plasma compared to the unhandled and uninfected control groups.

Conclusion. The present study showed that cortisol release in rainbow trout is associated with infection with the skin ciliate Ichthyophthirius multifiliis. Formalin, which is used to control the parasite infection, also elicited a high production of this immuno-suppressing hormone in the host.
\end{abstract}

Keywords: Rainbow trout, Ichthyophthirius multifiliis, formalin, stress, handling, cortisol, fish

\section{INTRODUCTION}

Ectoparasitic infections are generally considered to be a major problem in fish farming (Menezes et al. 1990, Hakalahti and Valtonen 2003). The ectoparasite Ichthyophthirius multifiliis Fouquet, 1876 is known to cause increased mortality in aquaculture world wide, resulting in economical losses for the fish farmers. Previous investigations have clearly established formaldehyde as an effective chemical against ectoparasitic infections caused by monogeneans and ciliates such as I. multifiliis in rainbow trout, Oncorhynchus mykiss (cf. Howe et al. 1995, Ostland et al. 1995, Buchmann and Kristensson 2003). As a result the chemical is used extensively in fish farms. Reports of acute physiological changes as a result of formaldehyde treatment in fish are limited. However, epithelial injuries and changes in mucous cell densities, due to short- and long-term exposure to formaldehyde have been demonstrated in rainbow trout (Lumsden et al. 1994, Buchmann et al. 2004).

It has clearly been demonstrated that the corticosteroid cortisol is secreted by fish as a response to harmful stimuli or stress (Schreck 1982, Pickering 1990, Nielsen and
Buchmann 1997, Barton 2000, Stoltze and Buchmann 2001). Further, elevated plasma cortisol levels in salmonid species such as Atlantic salmon, Salmo salar, have on several occasions been associated with a reduction of fish growth (Pickering 1990). However, information on the stress response in salmonids (plasma cortisol concentration), associated with parasitic infections and associated formaldehyde treatment, is limited (Stoltze and Buchmann 2001). It is also noteworthy that several experiments have suggested the possibility of fish being more susceptible to opportunistic pathogens as a result of injuries to the skin caused by formaldehyde treatment and elevated cortisol concentrations (Madsen and Dalsgaard 1999, Stoltze and Buchmann, 2001, Buchmann et al. 2004). The present work, therefore, aims to elucidate the connection between the stress response and infection, handling/confinement, and formaldehyde treatment of rainbow trout.

\section{MATERIALS AND METHODS}

Pathogen-free rainbow trout (Danish Centre for Wild salmon, Brusgaard, Jutland, West Denmark, Skinnerup

\footnotetext{
* Correspondence: Thomas Rohde Jørgensen, Department of Veterinary Pathobiology, Section of Fish Diseases, University of Copenhagen, Faculty of Life Sciences, Stigbøjlen 7, Frederiksberg, Denmark, phone: +45-35382769, fax: +45-35282711, e-mail: trj@life.ku.dk
} 
Mølle strain) were used throughout the experiment. Fish were fed $1 \% \mathrm{BW} /$ day pellet feed (Biomar) over the duration of the experiment, and acclimatized during a 3-week period prior to the experiment. At the start of the acclimation period, fish had a mean body weight of $36.1 \mathrm{~g}\left(s_{\bar{x}}=0.76\right)$ and a mean fork length of $11.9 \mathrm{~cm}\left(s_{\bar{x}}=0.31\right)$.

Fish were kept in $120 \mathrm{~L}$ tanks containing aerated, municipal water, recirculated by internal biofilters (Eheim, Germany). The temperature was kept at $12^{\circ} \mathrm{C}$ in a thermostat controlled room. Water was changed once a day (after blood sampling on day 8 and 16). Concentrations of $\mathrm{NH}_{3} /$ $\mathrm{NH}_{4}{ }^{+}$and $\mathrm{NO}_{2}{ }^{2-} / \mathrm{NO}_{3}^{-}$were monitored (Nitrat, Nitrit, Ammonium-Test, Merck, Germany).

Experiments were conducted in triplicates. A total of 360 rainbow trout were distributed in 12 tanks, each containing 30 fish. Fish tanks were divided into 4 groups, each comprising 3 tanks. Fish were kept at constant dark conditions. Blood was collected from 5 fish in each tank at day 8 and 16. The three experimental groups were treated according to the plan outlined below.

Group 1. Fish were kept unhandled and uninfected.

Group 2. Daily formaldehyde concentration of $120 \mathrm{ppm}$ (highest recommended concentration for treatment). The formaldehyde solution was removed after 60 minutes of static bath treatment, and replaced with municipal water. Internal biofiltres were removed during periods with formaldehyde treatment.

Group 3. Infections with the skin ciliate Ichthyophthirius multifiliis. Five infected rainbow trout were introduced into the tanks with uninfected fish at day 0 (cohabitation). Furthermore, five uninfected fish were introduced into all other tanks to maintain an equal number of fish in each group. Introduced fish were consequently marked (finclipped) to avoid sampling errors. Thus, the uninfected fish were subjected to infection at the time where infective theronts had been produced by trophonts leaving the skin of already infected fish (day 3). Parasite numbers were assessed macroscopically on day 16 .

Group 4. Fish were subjected to confinement stress (day 8 and 16) by netting 15 fish at a time and keeping them for one hour in one litre of aerated water (10-L tank). Blood

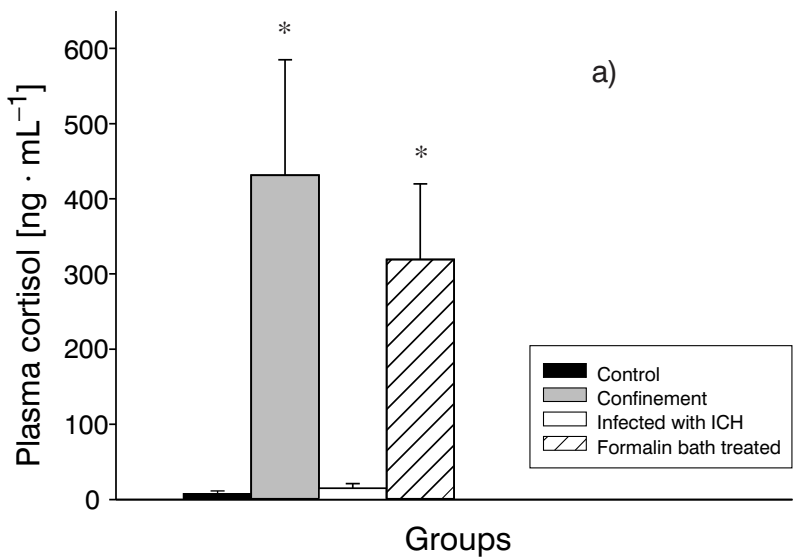

sampling was conducted immediately after. Thus, the confinement group served as a comparative positive control.

At each sampling point (days 8 and 16) 5 fish from each tank were rapidly netted and killed in an overdose of MS-222 (500 mg $\left.\cdot \mathrm{L}^{-1}\right)$. Using heparinized syringes, blood was rapidly collected from the caudal vessels and dispensed into $1.2 \mathrm{~mL}$ centrifuge tubes. Blood was centrifuged $(5 \mathrm{~min} \times 16000 \mathrm{~g})$ whereupon plasma was collected and stored at $-20^{\circ} \mathrm{C}$ until further analysis.

Plasma samples $(20 \mu \mathrm{L})$ from each fish were used for cortisol measurements. The cortisol concentration in plasma was measured using a competitive ELISA-kit (Cortisol kit, ElAgen, Adaltis, Italy), according to the manufacturer's instructions.

Cortisol data were tested for normality (Kolmogorov-Smirnov test for normality $(P<0.001)$, Sigma Stat, 2005). A nonparametric test (Kruskal-Wallis) One Way Analysis of Variance on Ranks, $(P<0.05)$, Sigma Stat 2005) was applied to test for differences between experimental groups. An All Pairwise Multiple Comparison Procedure (Dunn's Method, Sigmastat 2005) was applied to isolate the group or groups that differed significantly. A Mann-Whitney Rank Sum Test $(P<0.05)$ was used to compare the same groups after 8 and 16 days.

\section{RESULTS}

No mortality was recorded, in any of the groups, during the experimental period.

Day 8: Group 4 (confinement) and 2 (formalin bath treatment) demonstrated significantly higher plasma cortisol concentrations compared to group 1 (control) and group 3 (infection with I. multifiliis) $(P<0.05)$ (Fig. 1a).

Day 16: Group 4 (confinement), group 2 (formalinbath treated) and group 3 (infection with I. multifiliis) demonstrated significantly higher concentrations when compared to group 1 (control) $(P<0.05)$ (Fig. 1b).

Fish from group 1 (control) showed relatively low mean cortisol concentrations in plasma after both 8 and 16 days $\left(7.5 \mathrm{ng} \cdot \mathrm{mL}^{-1}\right.$ and $44.0 \mathrm{ng} \cdot \mathrm{mL}^{-1}$ respectively). However, fish from group 2 (formalin bath treated) demonstrated an elevated mean concentration of plasma

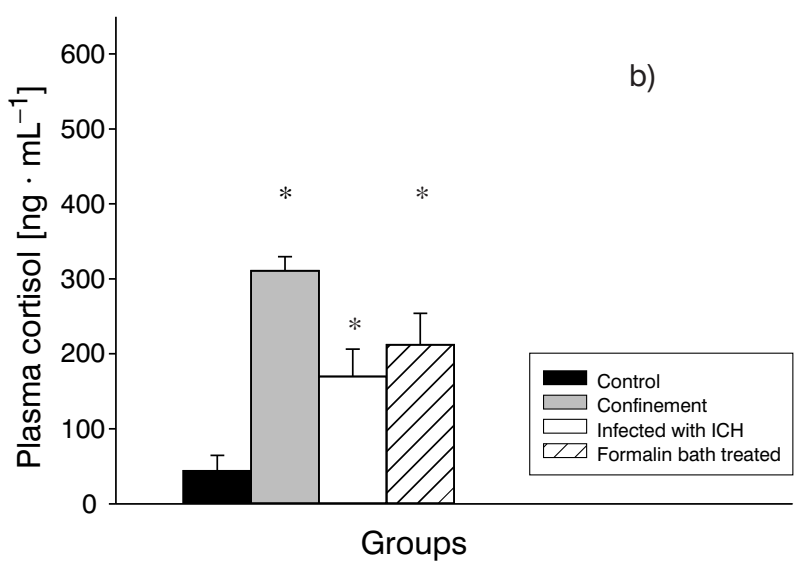

Fig. 1. Plasma cortisol concentration in each of the 4 experimental groups of rainbow trout on day 8 (a) and on day 16 (b); $\left(x \pm s_{\bar{x}}\right)(n=15)$ for all groups; $* P<0.05$ (different from control group) 
cortisol after both 8 and 16 days $\left(319.0 \mathrm{ng} \cdot \mathrm{mL}^{-1}\right.$ and $212.0 \mathrm{ng} \cdot \mathrm{mL}^{-1}$ respectively). Fish from group 3 (infection with $I$. multifiliis) showed relatively low mean cortisol concentrations after 8 days, but elevated concentrations after 16 days of exposure to the parasite $\left(14.9 \mathrm{ng} \cdot \mathrm{mL}^{-1}\right.$ and $170.0 \mathrm{ng} \cdot \mathrm{mL}^{-1}$, respectively). Thus, the group infected with I. multifiliis demonstrated a significant elevation in cortisol concentration from day 8 to day16 $(P<0.05)$. During this period the number of visible trophonts in the skin increased from 0 to approximately 100 in each fish. Fish from group 4 (confinement) showed highly elevated mean plasma cortisol concentrations after both 8 and 16 days (431.0 $\mathrm{ng} \cdot \mathrm{mL}^{-1}$ and $311.0 \mathrm{ng} \cdot \mathrm{mL}^{-1}$, respectively).

\section{DISCUSSION}

The present results confirm that rainbow trout respond to harmful stimuli by elevating plasma cortisol concentrations. Thus, it was found that not only I. multifiliis infection but also a generally accepted treatment against ectoparasites resulted in increased cortisol levels in rainbow trout. Cortisol concentrations found in this study were in accordance with previous concentrations found in juvenile Atlantic salmon and a wide range of salmonids (Pickering and Pottinger 1989, Nielsen and Buchmann 1997, Barton 2000, Cho and Heath 2000). Cortisol concentrations increased in response to confinement stress, which is in accordance with previous studies showing elevated cortisol concentration as a result of handling and confinement (Thomas and Robertson 1991, Pottinger et al. 1999, Barton 2000, Stoltze and Buchmann 2001). In the present study also formalin treated rainbow trout (120 ppm for $1 \mathrm{~h}$ ) showed highly elevated cortisol levels. The formalin concentration and exposure time used in the present study are in accordance with concentrations and treatment durations used in aquaculture, thus mimicking conditions and stress levels found in fish during treatment. Previous studies have demonstrated extensive damage to the epithelium as well as changes in skin composition as a result of formalin exposure (Buchmann et al. 2004). The present work further indicates that formalin, although antiparasitic, is causing adverse effects in rainbow trout. The study by Buchmann et al. 2004, demonstrated a significant elevated concentration of mucous cells after $1 \mathrm{~h}$ of formalin exposure at a concentration of $100 \mathrm{ppm}$. Scanning electron microscope pictures of the epithelium also revealed extensive damage and disorganisation following 1-h exposure at $300 \mathrm{ppm}$. In the present study, the group infected with I. multifiliis demonstrated a significant elevation in cortisol levels from day 8 to day 16 . Thus, the plasma cortisol concentrations of infected fish (after 16 days) were similar to formalin treated fish. The reason behind the relatively low cortisol levels at day 8 is a result of the lifecycle of $I$. multifiliis. Thus, the uninfected fish were subjected to infection at the time where infective theronts had been produced by trophonts leaving the skin of already infected fish. Thus, a time lag is expected between the introductions of infected fish, until high infection levels are found in naive fish.
From the present study, it seems that stress response is associated with infections caused by the ectoparasite I. multifiliis. This observation is interesting because only a few studies have been able to show induction of stress associated with ectoparasitic infections in fish (Stoltze and Buchmann 2001, Fast et al. 2006). The study by Stoltze and Buchmann 2001, illustrated a significant elevation of cortisol concentrations as a result of infection with the ectoparasite Gyrodactylus derjavini. Gyrodactylids actively attaches to a host and penetrate the epithelium, using their marginal hooklets, thereby creating similar osmotic disturbances as I. multifiliis (cf. Larsen and Buchmann 2006, Jørgensen et al. 2007). The present study thus indicates that cortisol release is associated with infection intensity. Formalin treatment clears the fish of ectoparasites, but it may leave the fish more susceptible to opportunistic pathogens as a result of injuries to the skin caused by formaldehyde treatment and at the same time leave the fish in an immuno-suppressed stage as a result of high cortisol concentrations (Pickering and Pottinger 1989). However, additional studies are needed to create conclusive results, as to the precise role of formaldehyde as a precursor of secondary infection. Furthermore, it is likely that an additive stress response can occur in cases where already infected and stressed fish are treated with high doses of formalin. The effect of such additive stress should be investigated in future studies. To elucidate if elevated cortisol should be considered chronic or acute during infection with I. multifiliis and treatment with formalin would also be a point of interest in future studies. Such studies could clarify to which extend cortisol acts as an immuno-suppressor in the chase described in the present work.

\section{ACKNOWLEDGEMENTS}

The present study is a part of the project FFS95-7 "Strategies to improve health and welfare in rainbow trout farming" supported by the Ministry of Food, Agriculture and Fisheries (Denmark). The work is associated with the research school and network SCOFDA, and the integrated project IMAQUANIM (EU-FP6).

\section{REFERENCES}

Barton B.A. 2000. Salmonid fishes differ in their cortisol and glucose responses to handling and transport stress. North American Journal of Aquaculture 62: 12-18.

Buchmann K., Kristensson R.T. 2003. Efficacy of sodium percarbonate and formaldehyde bath treatments against Gyrodactylus derjavini infestations of rainbow trout. North American Journal of Aquaculture 65: 25-27.

Buchmann K., Bresciani J., Jappe C. 2004. Effects of formalin treatment on epithelial structure and mucous cell densities in rainbow trout, Oncorhynchus mykiss (Walbaum), skin. Journal of Fish Diseases 27: 99-104.

Cho G.K., Heath D.D. 2000. Comparison of tricaine methanesulphonate (MS222) and clove oil anaesthesia effects on the physiology of juvenile Chinook salmon Oncorhynchus tshawytscha (Walbaum). Aquaculture Research 31: 537-546. 
Fast M.D., Muise D.M., Easy R.E., Ross N.W., Johnson S.C. 2006. The effects of Lepeophtheirus salmonis infections on the stress response and immunological status of Atlantic salmon (Salmo salar). Fish and Shellfish Immunology 21: 228-241.

Hakalahti T., Valtonen E.T. 2003. Population structure and recruitment of the ectoparasite Argulus coregoni Thorell (Crustacea: Branchiura) on a fish farm. Parasitology 127: 79-85.

Howe G.E., Marking L.L., Bills T.D., Schreier, T.M. 1995. Efficacy and toxicity of formalin solutions containing paraformaldehyde for fish and egg treatments. Progressive Fish-Culturist 57: 147-152.

Jørgensen T.R., Larsen T.B., Jørgensen L.G., Bresciani J., Kania P.W., Buchmann K. 2007. Characterisation of a low pathogenic form of Gyrodactylus salaris from rainbow trout. Diseases of Aquatic Organisms 73: 235-244.

Larsen T.B., Buchmann K. 2006. Host-specific in vitro colonisation of fish epithelia by gyrodactylids. Acta Ichthyologica et Piscatoria 36 (2): 113-118.

Lumsden J.S., Ferguson H.W., Ostland V.E., Bryne P.J. 1994. The mucous coat on gill lamellae of rainbow trout (Oncorhynchus mykiss). Cell and Tissue Research 275: 187-193.

Madsen L., Dalsgaard I. 1999. Reproducible methods for experimental infection with Flavobacterium psychrophilum in rainbow trout Oncorhynchus mykiss. Diseases of Aquatic Organisms 36: 168-176.

Menezes J., Ramos M.A., Pereira T.G., Moreira da Silva A. 1990. Rainbow trout culture failure in a small lake as a result of massive parasitosis related to careless fish introductions. Aquaculture 89: 123-126.

Nielsen M.E., Buchmann K. 1997. Association between immunisation, reduced weight gain and plasma cortisol concentra- tions in juvenile Baltic salmon (Salmo salar). Acta Veterinaria Scandinavica 38: 275-282.

Ostland V.E., Byrne P.J., Speare D.J., Thorburn M.A., Cook A., Morrison D., Ferguson H.W. 1995. Comparison of formalin and chloramine-T for control of a mixed gill infection (bacterial gill disease and ichthyobodiasis) in rainbow trout. Journal of Aquatic Animal Health 7: 118-123.

Pickering A.D., Pottinger T.G. 1989. Stress responses and disease resistance in salmonid fish: Effects of chronic elevation of plasma cortisol. Fish Physiology and Biochemistry 7: 253-258.

Pickering A.D. 1990. Stress and the suppression of somatic growth in teleost fish. Pp. 473-471. In: Epple A., Scanes C.G., Stetson M.H. (eds.) Progress in Comparative Endocrinology. (Vol. 342 of: Progress in clinical and biological research.) Wiley-Liss, New York.

Pottinger T.G., Yeomans W.E., Carrick T.R. 1999. Plasma cortisol and 17 beta-oestradiol levels in roach exposed to acute and chronic stress. Journal of Fish Biology 54: 525-532.

Schreck C.B. 1982. Stress and rearing of salmonids. Aquaculture 28 : 241-249.

Stoltze K., Buchmann K. 2001. Effect of Gyrodactylus derjavi$n i$ infections on cortisol production in rainbow trout fry. Journal of Helminthology 75: 291-294.

Thomas P., Robertson L. 1991. Plasma cortisol and glucose stress responses of red drum (Sciaenops ocellatus) to handling and shallow water stressors and anaesthesia with MS-222, quinaldine sulphate and metomidate. Aquaculture 96: 69-86.

Received: 24 April 2007

Accepted: 16 May 2007

Published electronically: 15 July 2007 